\title{
Evaluating the Efficacy of an Attachment-Informed Psychotherapeutic Program for Incarcerated Parents
}

\author{
N. LAURA KAMPTNER \\ California State University, San Bernardino \\ FAITH H. TEYBER \\ California State University, San Bernardino \\ NICHOLAS J. ROCKWOOD \\ Ohio State University \\ DOLLY DRZEWIECKI \\ California State University, San Bernardino
}

\begin{abstract}
An attachment-based, psychotherapeutic parent education course was created for incarcerated mothers and fathers to help improve their ability to provide positive parenting and a more stable home environment for their children. The current study assessed the effects of this parenting curriculum on parents' reported tendencies to be abusive, their sense of efficacy and satisfaction as a parent, their psychological distress, and their knowledge of child development and positive child guidance. Results of pre-post assessments showed a significant improvement in parents' reported sense of efficacy and satisfaction in the parenting role; their knowledge, skills, and behavior as a parent; their understanding of child development; their knowledge of alternatives to using corporal punishment; establishing appropriate parent-child boundaries; and they were less likely to view their child's independence as a threat. Females showed a significant decrease in distress symptoms. Results are discussed in terms of the need for effective, high-quality parent education as an important component of intervention programs that aim to improve the developmental outcome for children of incarcerated parents.
\end{abstract}

Keywords: parent education; children of incarcerated parents; intergenerational transfer of parenting patterns

The number of children in the U.S. with parents incarcerated in prisons increased by almost $80 \%$ between 1991-2007 to more than 1.7 million children (Glaze \& Maruschak, 2008; Maruschak, Glaze, \& Mumola, 2010). It is estimated that there are millions of additional children affected by parental incarceration in jails (Kemper \& Rivara, 1993). Indeed, the Center for Children of Incarcerated Parents estimates that more than 10 million U.S. children have experienced parental incarceration (Johnston, 2012). There is considerable evidence that parental incarceration has a profound, negative impact on children, including increasing their risk at least threefold of becoming involved with the criminal justice system (compared to children whose parents have never been incarcerated) (e.g., Bilchik, Seymour, \& Kresher, 2001; Conway \& Jones, 2015; Eddy \& Reid, 2003; Farrinton et al., 2001; Huebner \& Gustafson, 2007; Jarvis, Graham, Hamilton, \& Tyler, 2004; Johnston, 1995; Lipsey \& Derzon, 1998; Murray \& Farrington, 2005, 2008; Poehlmann, 2005a, 2005b; Trice \& Brewster, 2004; Turney, 2014). In fact, research suggests that parental incarceration may have more deleterious effects on children than either parental divorce or death (Turney, 2014). Children of incarcerated parents are more likely to exhibit emotional and behavioral problems compared to children whose caregivers have never been arrested (Phillips \& Dettlaff, 2009). They tend to exhibit both internalizing (e.g., depression, withdrawal) and externalizing (e.g., ADHD, stealing, fighting) behaviors (Dallaire, 2007; Fritsch \& Burkhead, 1981; Murray \& Farrington, 2008; Myers, Smarsh, Amlund-Hagen, \& Kennon, 1999; Raimon, Lee, \& Gentry, 2009; Turney, 2014), and are more likely to have poor academic performance due to a number of school-re- 
lated problems including disruptive behavior, suspensions from school, and increased truancy (e.g., Murray \& Farrington, 2005; Phillips \& Harm, 1996; Raimon et al., 2009; Trice \& Brewster, 2004). Also, when their parents are arrested, many children behave in even more emotionally and behaviorally disordered ways, especially when their new caregiving situations are unstable (e.g., Nesmith \& Ruhland, 2008; Phillips \& Harm, 1997; Poehlmann, 2005a; Dallaire, Loper, Poehlmann \& Shear, 2010). The instability of their new caregiving situation is a likely outcome since mothers in prison or jail often have difficult pre-incarceration histories including sexual, physical, and substance abuse, mental illness, medical problems, and homelessness (Glaze \& Mauschak, 2008; Mumola \& Karberg, 2006).

Factors such as low SES, family instability, low academic achievement, living in a poor/disorganized neighborhood, and engaging with delinquent peers have also been found to contribute to the increased risk of these children eventually becoming involved with the justice system (e.g., Henry, Caspi, Moffitt, \& Silva, 1996; Leventhal \& Brooks-Gunn, 2000; Odgers et al., 2008; see also Simpson, Yahner, \& Dugan, 2008). In addition, family factors such as parenting style contribute to the risk of delinquency, antisocial behavior, and conduct problems in children which increase their risk of future involvement with the justice system (e.g., Dallaire, 2007; Moffitt, Poulton, \& Caspi, 2013; Myers et al., 1999, Odgers et al., 2008; Poulton, Moffitt, \& Silva, 2015): whereas "authoritative" parenting and a secure parent-child attachment relationship (i.e., supportive, warm, responsive parenting characterized by strong parent-child bonds) are negatively related to delinquent and antisocial tendencies in children and adolescents, "authoritarian" parenting and insecure parent-child bonds (i.e., harsh, punitive, insensitive, unresponsive, and rejecting parenting) are linked to delinquent and antisocial behavior, conduct disorder, behavior problems, mental health problems, risky behavior during adolescence, and impulse control problems (e.g., Barnes \& Farrell, 1992; Farrington et al., 2001; Gerhardt, 2015; Hoeve, van der Put, \& van der Laan, 2012; Juang \& Silbereisen, 1999; Sroufe, Egeland, Carlson, \& Collins, 2005). These data highlight the relevance of parenting quality in children's future involvement with the justice system $^{1}$.

Children whose mothers become incarcerated are at greater risk of living with a caregiver who abuses drugs, has more mental health problems, is poorly educated, engages in domestic violence, frequently changes residences, and lives in poverty (Phillips \& Dettlaff, 2009). (The incarceration of mothers is especially disruptive because mothers are usually the primary caregivers prior to their arrest, so their children become placed with another caregiver, e.g., Johnston, 1995; Mackintosh, Myers, \& Kennon, 2006). Thus, children of incarcerated women are at high risk for receiving poor parenting prior to incarceration for a number of reasons including poverty (Gabel \& Johnston, 1995; Kampfner, 1995), instability in family life that often involves living with multiple caregivers (Johnston, 1995; Phillips \& Bloom, 1998; Raimon et al., 2009), domestic violence (Greene et al., 2000), community violence (Smarsh \& Myers, 2001), physical and sexual abuse (Green et al., 2000), substance abuse, and criminal behavior (Greene et al., 2000; Johnston, 1992; Murray \& Farrington, 2008; Wilson \& Howell, 1993).

Children of incarcerated fathers are at high risk for growing up in a single mother/ fatherless household as incarcerated fathers tend to have little or no contact with their children after birth, are less likely to marry or cohabit with the child's mother, and are less likely to contribute substantial economic resources to their child's household since labor force participation is greatly diminished by having a criminal record (e.g., Western \& McLanahan, 2000).

\section{Early Life Histories of Incarcerated Parents}

Research studies collectively show that risk factors for incarceration include coming from a background of poverty and ethnic minority status, growing up with dysfunctional parents and poor-quality parenting (e.g., abusive, neglectful, drug and alcohol addicted), early instability (including multiple moves and foster care placement), low educational attainment, mental health problems, substance abuse, and experiencing multiple types of abuse including physical, sexual, and emotional abuse, as well as neglect (e.g., Besemer, van der Geest, Murray, Bijleveld, \& Farrington, 2011; Elkins, Iacono, Doyle, \& McGue, 1997; Greenfield \& Snell, 1999; Piquero, Moffitt, \& Wright, 2007; Poulton et al., 2015). Other risk factors include certain personality characteristics such as poor self-control, neurocognitive deficits including hyperactivity problems and learning disabilities (with boys at greater risk for these than girls), child conduct/behavior problems, associating with 
delinquent peers, family factors and stresses such as living in a non-intact family/single parent household, parent loss, having a teen parent (Elkins et al., 1997; Henry et al., 1996; Krueger et al., 1994; Messer, Goodman, Rowe, Meltzer, \& Maughan, 2006; Murray, Irving, Farrington, Colman, Bloxsom, 2010; Trzesniewski et al., 2006; Wright, Caspi, Moffitt, \& Silva, 1999) and having a parent with a criminal history ${ }^{2}$ (e.g., Chesney-Lind, 1997; Johnston, 1991; Kates, Gerber, \& Casey, 2014; Messer et al., 2006; Mumola, 2000; Myers et al., 1999; Wasserman, 2000; Wilson \& Howell, 1993). Studies similarly suggest that the main predictors of incarceration for males include the early background experiences of poverty, ethnic minority status, low maternal education/ unemployment, dysfunctional parenting (e.g., abusive, neglectful), growing up in a father-absent household, residential instability, early behavioral/conduct problems (including adolescent delinquency), poor academic ability and low educational attainment (including poor literacy and dropping out of high school), unemployment, and drug and alcohol abuse (e.g., Bailey \& Hayes, 2006; Drakeford, 2002; Harper \& McLanahan, 2004; Ou \& Reynolds, 2010; Rogers-Adkinson et al., 2008; Rumbaut, 2005; Satterfield et al., 2007; Sourander et al., 2006; West, Denton, \& Germano-Hausken, 2000; Wildeman \& Western, 2010). The tragic early life experiences of incarcerated parents and the instability of their current life experiences diminish their ability to provide positive, skilled parenting for their own children: not surprisingly, studies show that children of incarcerated parents are more likely to experience attachment disruptions and disorganized attachments (Dallaire, 2007; Myers et al., 1999). Taken together, these findings suggest that if parents were more competent in their parenting skills, fewer problematic behaviors in children would develop, thereby helping to improve their developmental outcome and also lessen the risk of them becoming justice-involved as they become older (e.g., Heckman, 2010; Patterson, Reid, \& Dishon, 1992; Reid, Patterson, \& Snyder, 2002; Turner \& Peck, 2002).

\section{The Need For (and Benefits of) Parenting Education}

Studies suggest a number of benefits of parenting education for incarcerated parents including improving family stability, strengthening family bonds, and teaching positive parenting practices which strengthen parent-child relationships and improve child outcomes (Sandifer, 2008). The data show that children's social competence and attachment security is impacted largely by early parenting experiences; in particular, warm, supportive parenting (Belsky, Steinberg, \& Draper, 1991; Berlin \& Cassidy, 2003; Calkins, 2004; Rispoli, McGoey, Kozial, \& Schreiber, 2013; Roisman \& Fraley, 2008, 2012). In addition, teaching parenting skills and strengthening mother-child relationships for mothers with drug-abuse offenses is reported to reduce recidivism (Palmer, 1996; Rudel \& Hayes, 1990). Parenting programs also help incarcerated inmates develop their interpersonal skills (Klein \& Bahr, 1996; Wilczak \& Markstrom, 1999), which can have a positive impact on partner relationships and family stability. In addition, the data show that involving inmates in educational programs reduces inmates' disciplinary problems (Perez, 1996), reduces recidivism (Gordon \& Weldon, 2003), and improves self-esteem and parenting attitudes (Thompson \& Harm, 2000). Parenting education can also improve parents' mental health and well-being, including self-efficacy, depression, anxiety, and stress (e.g., Kaminski, Valle, Filene, \& Boyle, 2008). Thus, teaching parenting skills to inmates may be one pathway of a broader intervention strategy aimed at helping to improve parental mental health, strengthen family bonds, deter parents' re-offending, and lessen the risk of their children becoming involved in the justice system.

Many correctional institutions offer parenting programs, but most focus on changing parenting skills versus changing parents' attitude toward parenting - i.e., using a relational perspective toward parenting (e.g., Arnsbro, 2008). The nature of the parenting program taught is significant, since research supports that strengthening families, especially parent-child attachment (wherein the caregiver provides children with a "secure base", i.e., responsiveness that keeps the child's "mind in mind") is a critical factor in facilitating children's psychological well-being, successful peer relationships, emotional self-regulation, empathy for others, and academic endeavors (Cassidy \& Shaver, 2016). Further, the quality of the parent-child attachment bond has also linked to delinquency, antisocial disorders, and conduct disorders (e.g., Hoeve et al., 2012; Sroufe et al., 2005; D'Andrea, Ford, Stolbach, Spinazzola, \& van der Kolk, 2012). Given that children of incarcerated parents are at least three times more likely to become justice-involved (compared to children whose parents have never been incarcerated (e.g., Conway \& Jones, 2015), and the knowledge that incarcerated individuals have experienced much family disruption including frequent moves, many foster care placements, and various types of abuse and neglect (Greenfield \& Snell, 1999), we created a parenting curriculum that focuses on the 
critical, positive impact of early attachment security. This curriculum involves providing positive parenting education to parents in the hope that positive parenting education combined with group support that targets common sources of difficulty and relapse (e.g., substance abuse, challenging interpersonal relationships, addressing the needs of their children in developmentally-appropriate ways) may help to improve these parents' abilities to provide stable and consistent environments for their children.

The child development literature is unambiguous about the importance and positive impact of early attachment security (i.e., positive, warm, caregiving experiences): secure attachment facilitates the development of children's emotional, cognitive, and brain development, as well as academic success (e.g., Sroufe et al., 2005). The research literature supports that if parents can be trained in, and provide, their children with positive parenting approaches, they may be better able to provide a stable home environment for their children which can help facilitate children's well-being and decrease their children's risk of becoming justice-involved.

\section{Purpose of Study}

The current study was conducted to assess the impact of a psychotherapeutic, attachment- based parent education course on parents' reported tendencies to be abusive, their sense of efficacy and satisfaction in their parenting role, their psychological distress, and their knowledge of child development and positive guidance strategies. Pre-post data were collected for each participant on these factors. We anticipated that after participating in the course, parents would report fewer abusive propensities, more satisfaction and efficacy in their parenting roles, and greater knowledge of child development and positive guidance strategies.

\section{Method}

\section{Participants}

Participants included $430^{3}$ parents/guardians/other caregivers (54.8\% females, $45.2 \%$ males; mean age $=30.1$ years) who were serving jail sentences at the Glen Helen Rehabilitation Center (one of four jails in San Bernardino County) and who were enrolled in the parenting class from 2010-2016. Most were Hispanic or Caucasian, unmarried, with low educational attainment. Most were unemployed and living at or below the poverty level at the time of incarceration (Table 1).

Over half (58.3\%) reported they were unemployed prior to incarceration. One-third (33.6\%) had reportedly experienced abuse (verbal, physical, sexual, emotional) as a child by a person outside the family, while $44.3 \%$ reported they were abused (verbal, physical, sexual, emotional) as a child by a family member. Slightly over half $(51.1 \%)$ had witnessed abuse (verbal or physical) between their parents as a child. Seventy-nine percent of participants stated they have (or had in the past) a problem with alcohol and/or other drug abuse.

\section{Materials}

Parenting curriculum. We designed a 48-hour attachment-based, psychotherapeutic parent education course for parents at the Glen Helen Rehabilitation Center, a jail located in the north end of San Bernardino, CA. The course is taught to groups of 10-25 mothers and fathers in 4-week cycles by students in the second year of their master's program in Clinical-Counseling Psychology who are trained by clinical psychologists with extensive clinical experience. The students receive weekly clinical supervision and use curriculum developed by a Ph.D in developmental psychology and a Ph.D. in clinical psychology.

During each 4-week cycle, the class met for three hours per day, four days per week. The course was specifically designed for this population and is informed by research-based information on attachment, child growth and development, effective parenting strategies for children of different ages, creating safe and healthy home environments, parent development (highlighting parental attachment history to help participants understand the intergenerational transmission of trauma and attachment styles), and family unification issues. The centerpiece of the curriculum is the importance of warm, sensitively-attuned, responsive caregiving for the optimal development and well-being of individuals (i.e., attachment security) to strengthen parent-child relationships and thereby improve the developmental outcome of the children of these incarcerated parents (Cassidy \& Shaver, 2016; Crittenden, 2008; Juffer, Bakermans-Kranenburg, \& vanIJzendoorn, 2008; Perry, 2002; Siegel \& Hartzell, 2013; Sunderland, 2006). The curriculum also incorporates the latest research on early brain development which emphasizes the importance of early parental sensitivity (e.g., Cozolino, 2005; 
Siegel \& Hartzell, 2013). The curriculum is based on research on incarcerated parents in general, as well as the extensive data we have collected on individuals throughout the local county jail system, so the curriculum is sensitive to issues relevant to the incarcerated population we are serving.

Measures. There were four pre-post assessments administered to participants in the parenting classes. Pretest assessments were administered on the first or second day of each class; posttest assessments were administered on the last day of the class. Participants also completed a background information form as a part of their pre-test assessments and an open-ended class evaluation on the last day of the class as a part of their post-test assessments.

Table 1

Background Information on Parenting Class Participants ( $N=430$ )

Respondent Characteristic

Parenthood status

Parent

92.7

Stepparent

Parent-to-be

Guardian

Not a parent

$\%$

1.4

1.4

.7

3.7

\section{Ethnicity}

Hispanic

41.8

Caucasian

35.7

African-American $\quad 12.2$

Bi-racial

Native American

Asian

Other

2.6

.8

.6

6.4

Marital status

Single

45.6

Married

18.1

Engaged

15.9

Separated/divorced

11.0

$\begin{array}{ll}\text { Widowed } & 1.7\end{array}$

$\begin{array}{ll}\text { Other } & 7.6\end{array}$

Education

Completed a graduate degree $\quad .5$

Completed a B.A./B.S.degree $\quad 1.5$

Completed an A.A./A.S. degree $\quad 2.8$

Some college 21.0

Vocational/trade school 5.3

Graduated from high school $\quad 12.0$

Completed a GED $\quad 13.5$

Hadn't finished high school $\quad 43.5$

Annual household income before incarceration:

Less than $\$ 10 \mathrm{~K}$

S10-25K

\$25-40K

S40-50K

More than $\$ 50 \mathrm{~K}$ 
The first pre-post assessment was the revised version of the Adult-Adolescent Parenting Inventory (AAPI-2) (Bavolek \& Keene, 2001), a standardized measure that has been used in many settings including prisons to measure the effectiveness of parent education programs (Harm \& Thompson, 1997; Sandifer, 2008). The 40-item instrument has five constructs that describe parent-child skills and attitudes: Parental Expectations (7 items), which examines parents' understanding of child growth and having appropriate expectations of their child; Parental Empathy (10 items), which assesses parents' ability to demonstrate empathy toward children's needs; Corporal Punishment (11 items), which evaluates parents' understanding of alternatives to corporal punishment; Parent-Child Role Reversal (7 items), which taps the parents' attitude toward appropriate parent-child boundaries; and Power/Independence (5 items), which evaluates parents' ability to value their child's independence without seeing it as a threat to their authority. Participants responded to items on a 5 -point likert scale $(1=$ strongly agree; $5=$ strongly disagree). This instrument can be used to assess parenting attitudes and child rearing practices by assessing the degree to which respondents endorse parenting behaviors and attitudes known to contribute to child abuse and neglect. Conners et al. (2006) report alpha reliability coefficients ranging from .50 (for Oppressing Children's Power and Independence) to .75 (for Lack of Empathy and Value of Corporal Punishment), with a coefficient of .85 for the full scale.

The Parenting Sense of Competence (PSOC) scale (Johnston \& Mash, 1989), a 17-item scale, was used to assess parents' sense of efficacy and satisfaction as a parent. Satisfaction is defined as the parent's enjoyment or liking of their role as a parent; Efficacy is defined as the parents' perceived competence in their parenting role (Gilbaud-Wallston \& Wanderson, 1978). Participants respond to each item on a 6-point likert scale ( $1=$ strongly disagree; $6=$ strongly agree). Parenting self-efficacy has been associated with parenting competence and children's behavioral outcomes (Jones \& Prinz, 2005). Research studies suggest that when parents feel confident in their parenting ability, they are more likely to use effective parenting practices, which yield positive outcomes for their children (e.g., Gilmore \& Cuskelly, 2009; Johnson \& Mash, 1989; Ohan, Leung, \& Johnson, 2000). Johnston and Mash (1989) reported internal consistency of .77 for the Satisfaction dimension and .76 for the Efficacy dimension. Similarly, Ohan, Leung, and Johnston (2000) reported internal consistency for mothers on both the Efficacy and Satisfaction scales as .80 and for fathers, internal consistency of the Efficacy scale was reported as .77 and for the Satisfaction Scale as .80.

The Survey of Parenting Practices (SPP) (Shaklee \& Demarest, 2002) was used to assess parents' knowledge, feelings of competency, skills, and behavior. The 12-item scale was originally developed by faculty at the University of Idaho as a part of their assessment protocol for the Parents as Teachers (PAT) parenting program; studies show the scale to be reliable and valid (www.ParentsAsTeachers.org). Participants responded to the items on a likert-type scale $(0=$ low; $6=$ high $)$. For the current study, we assessed parents at the beginning and again at the end of the class (rather than simply assessing parents' pre-class knowledge retrospectively as suggested by the authors of this scale).

The Brief Symptom Inventory-18 (BSI-18) (Derogatis, 2000) was used to assess general psychological distress. The BSI-18 is an 18-item self-report measure that is a shortened form of the 53-item BSI (Derogatis \& Spencer, 1982), originally derived from the SCL-90-R (Derogatis, 1994). The BSI-18 was developed as a screening instrument for the most common psychological disorders, i.e., somatization (SOM), depression (DEP), and anxiety (ANX) (Derogatis, 2000), and yields either subscale scores or a global score of general distress (GSI). Participants respond to each item on a 5 point likert scale ( $0=$ not at all; $4=$ extremely). Internal consistency is reportedly .74 (SOM), .79 (ANX), .84 (ANX), and .89 (GSI) with reliability estimates for all four scores over a six week period between .68-.91. Concurrent validity with the SCL-90 for all four scores is $>.90$ (Derogatis, 2000).

Finally, participants completed a background information form on the first day of class that requested information about their age, gender, marital status, ethnicity, number/ages of children (including if they had lived with their children pre-incarceration), level of education, employment status before incarceration, drug/ alcohol abuse, and childhood experiences (e.g., whether they had experienced abuse and/or witnessed domestic violence).

\section{Data Analysis}

For each outcome variable, a 2 X 2 mixed design ANOVA was used to assess the effects of pre-post 
testing (a within-subjects factor), gender (a between-subjects factor), and the interaction between pre/post testing and gender. The pre/post tests assess whether, on average, the participants scored significantly different on the posttest relative to the pretest. Thus, the pre/post effect is indicative of the effectiveness of the program, collapsing across both genders. The main effect of gender tests whether males and females scored significantly different from each other, collapsing across pretest/ posttest, and the interaction allows testing of whether the average change in scores from pretest to posttest differs depending on the gender of the participant. Thus, a significant interaction effect is indicative that the effectiveness of the program is dependent, or conditional, on the gender of the participant.

A limitation of the current research design is the lack of a control group to compare the program participants to. As such, the effectiveness of the program may be overestimated since the average difference between pretest and posttest scores is compared (and tested) relative to 0 (i.e., no change), as opposed to relative to the average difference in a control group. So, any differences between pretest and posttest scores that would be expected to occur within a control group (possibly due to confounding variables) cannot be factored into the analysis.

\section{Results}

Pre-post assessments. The differences for all pre/post tests, when split by gender, were normally distributed. There were a total of 10 outliers $(-3.29>z>3.29)$ for all criterion variables that were removed during the analysis that used that criterion variable. Further, the assumption of homogeneity of variance was not violated using the 4:1 rule. For each analysis, cell means, standard deviations, and ANOVA results for the pre/ post tests are shown in Table 2. Results showed that, with gender collapsed, participants scored significantly higher $(p<.05)$ on the posttests than the pretests for all dependent variables except the Brief Symptom Inventory (BSI) and the Empathy subscale from the Adult-Adolescent Parenting Inventory (AAPI-2). For the BSI, participants scored significantly lower on the posttest than the pretest $(p=.001)$, which was in the expected direction indicating a decrease in psychological distress. For the Empathy subscale, the mean difference was in the expected direction and showed a trend, but it was not statistically significant $(p=.06)$.

Thus, adults' reported sense of efficacy and satisfaction as a parent improved (i.e., the PSOC scale), as did their knowledge, skills, and behavior as a parent (i.e., the SPP scale). Class participants also improved their understanding of child development and having appropriate expectations (Parental Expectations subscale), alternatives to using corporal punishment (Corporal Punishment subscale), appropriate parent-child boundaries (Parent-Child Role Reversal subscale), and were better able to value their child's independence instead of viewing it as a threat (Power/Independence subscale). The magnitudes of these effects varied considerably, with the most notable being for the PSOC $\left(\eta^{2}=.30\right)$ and the SPP $\left(\eta^{2}=.25\right)^{4}$. There were also small to medium effect sizes for the Power/Independence subscale $\left(\eta^{2}=.06\right)$, the Corporal Punishment subscale $\left(\eta^{2}\right.$ $=.05)$, the BSI $\left(\eta^{2}=.05\right)$, and the Parent-child Role Reversal subscale $\left(\eta^{2}=.03\right)$.

The interaction between pre/post testing and gender was statistically significant for the SPP, the PSOC, and the BSI (Table 3). For the SPP and the PSOC, although both males and females scored higher on the posttest than the pretest (with the expected inverse for the BSI), the difference between posttest and pretest scores was greater for females than males. For the BSI, this interaction explained an additional $4.37 \%$ of variance. Male participants scored roughly the same on the posttest $(M=1.56, S D=0.61)$ as the pretest $(M=$ $1.58, S D=0.55)$, while female participants scored lower on the posttest $(M=1.56, S D=0.50)$ than the pretest $(M=1.85, S D=0.77)$ (indicating a decrease in distress symptoms).

\section{Discussion}

The composition of our incarcerated parents is similar to that reported in other studies (e.g., Kjellstrand et al., 2012). Most have histories that include personal alcohol and drug abuse, and most have experienced trauma; they also come from dysfunctional families where their parents used alcohol and drugs and have a history of criminal behavior (Sandifer, 2008). This history strongly suggests that most incarcerated individuals are recipients of poor-quality parenting themselves, and lacked parenting role models (Arnsbro, 2008; Wilson et al., 2010). Thus, they are at high risk for providing dysfunctional parenting for their own children (Codd, 2007), suggesting that the need for high-quality, effective parenting education for those incarcerated may be 
an important component of intervention programs designed to help decrease the negative impact of parental incarceration on children, including their future involvement with the justice system. That is, programs that strengthen parent-child relationships and promote positive, responsive parenting may help to improve the mental and physical health outcomes and overall adjustment of children whose parents are incarcerated (e.g., Newman, Fowler, \& Cashin, 2011).

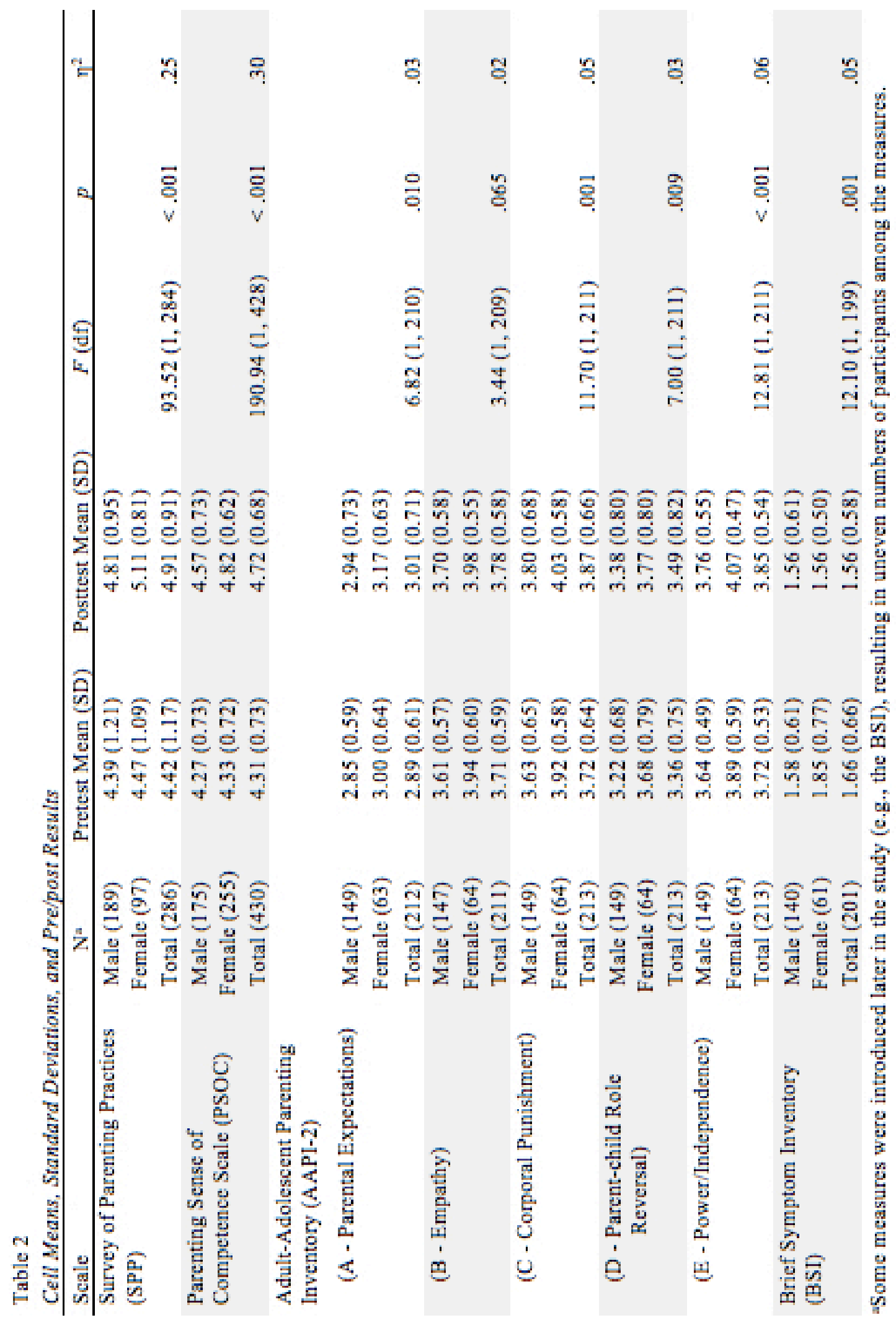

The results of the pre-post assessments in the current study suggest that our intensive attachment-based, psychotherapeutic parenting class was effective in increasing participants' reported sense of efficacy and sat- 
isfaction as a parent, and reduced their symptoms of psychological distress. This is similar to the findings of Loper and Tuerk (2011) and Dowling and Gardner (2005) who found that mothers in their studies who completed a parenting class reported reduced parenting stress and a reduction in symptoms of mental distress. Additional research suggests that high maternal efficacy beliefs are associated with effective parenting behaviors (Coleman \& Karraker, 2000; Raikes \& Thompson, 2005). These findings are important since research shows

Table 3

ANOVA Results: Gender and Pre/Post Interaction Effects

\begin{tabular}{ccccc}
\hline & & & & \\
Effect & DV & & & \\
& SPP & $4.05(1,284)$ & .045 & $\eta^{2}$ \\
\hline Pre/post ${ }^{*}$ Gender & PSOC & $12.21(1,428)$ & .001 & .01 \\
& BSI & $9.64(1,199)$ & .002 & .02 \\
& AAPI-A & $0.04(1,210)$ & .396 & .00 \\
& AAPI-B & $0.00(1,209)$ & .408 & .00 \\
& AAPI-C & $0.21(1,211)$ & .427 & .00 \\
& AAPI-D & $1.02(1,211)$ & .452 & .00 \\
& AAPI-E & $0.01(1,211)$ & .445 & .00 \\
\hline
\end{tabular}

that parental efficacy and satisfaction in parenting are related to child well-being (Coleman \& Karraker, 2003). Other researchers also note the importance of increasing parental sense of competence (PSOC) and decreasing mental distress. Knoche, Givens, and Sheridan (2007), for example, noted that high scores on the PSOC seemed to act as a buffer against cognitive deficits in the children they assessed. Further, studies indicate that there is a link between maternal depression and negative child outcomes such as insecure attachment, behavioral problems, and problems with cognitive and motor development (Field et al., 1995; Murray, 1992; Petterson \& Albers, 2001). Thus, reducing symptoms of mental distress in mothers may be another important by-product of participating in parenting training programs.

In our study, we found that parental knowledge of child development and child guidance skills increased-- especially for the female inmates - from taking this parent education class. In addition, the program was found to be effective in decreasing the majority of the behaviors and attitudes found to be associated with child abuse and neglect (Bavolek \& Keene, 2001), e.g., having inappropriate expectations of their child, understanding alternatives to corporal punishment, having appropriate parent-child boundaries, and not viewing their child's developing independence as a threat. The lack of statistical significance for the empathy construct may be due to participants being less likely to have received empathy growing up (due to early dysfunctional parenting) and therefore having a more difficult time being able to develop empathy for others since this is a new "construct" for them. These findings are, in part, similar to other research with incarcerated populations, e.g., Harm, Thompson, and Chambers (1998) who also found no statistical changes in pre-post testing among their subjects following a 15-week parenting program. The other findings are consistent with much of the literature on incarcerated parents in showing the effects of parent education. For example, Palusci et al. (2008) found, as we did, that the incarcerated participants in a parenting program they conducted improved their knowledge and attitudes regarding parenting, especially in inappropriate child expectations, and use of corporal punishment. The changes in views of corporal punishment and increase in knowledge of positive child guidance is noteworthy in that harsh and insensitive parenting has consistently been linked to increased risks for behavior problems in children (Campbell, Shaw, \& Gilliom, 2000; Shaw et al., 2003) while sensitive, child-centered parenting has been associated with less risk for behavior problems (Calkins et al., 1998).

Gender differences on the pre-post assessments for the SPP, the PSOC, and the BSI (with females but not males showing a significant difference in the expected directions) suggest that the parenting class had a greater "impact" for females than males in increasing their sense of efficacy, feelings of competency and satisfaction as parent, parental knowledge and skills,and decreasing their symptoms of distress. These findings 
may be related to the fact that females are more likely to be the primary caregivers of children, and that the parenting role may be a more salient one for females than for males.

The findings of this study as discussed above should be interpreted somewhat cautiously, though, as the use of a pre/post design without a matched control group clouds our ability to definitively conclude that the changes in scores were due to the intervention or to other confounding factors. Further, since the current study did not include pre/post observed parent-child interactions, it is unclear whether the observed change in parents' reported attitudes about child guidance and other beliefs translated to actual changes in parent behavior toward the child.

Since the research literature supports that one pathway to help improve the developmental outcome of children of incarcerated parents is by intervening with parents early, we see helping these parents early on as critical. This literature demonstrates that an attachment-based parenting program coupled with teaching positive child guidance strategies and child development can improve parent-child relationships and child outcome (e.g., Cassidy \& Shaver, 2016; Crittenden, 2008; Juffer et al., 2008; Perry, 2002, 2005; Siegel \& Hartzell, 2013; Sroufe et al., 2005; Sunderland, 2006). Poor-quality parenting, especially avoidant and disorganized parent-child attachments, have been linked to a number of the risk factors associated with later criminal behavior, e.g., poor impulse/self-control, negative emotionality, aggression, poor self-esteem, problems in peer relationships, mental health problems, poor academic achievement, conduct/behavior problems including antisocial tendencies, and substance abuse (e.g., Cassidy \& Shaver, 2016; Gerhardt, 2015; Guttmann-Steinmetz \& Crowell, 2006; Heckman, 2010; Mikulincer \& Shaver, 2007; Sroufe et al., 2005; Sroufe, Duggal, Weinfeld, $\&$ Carlson, 2000). Thus, this attachment-based curriculum is particularly relevant for those who are or have been incarcerated as the intergenerational transfer of dysfunctional attachment patterns, including the inability to develop self-reflection and emotional regulation, are typically at the heart of these individuals' problems (e.g., Arnsbro, 2008; Makariev \& Shaver, 2010). Our parenting curriculum is based on this research and has as its goals the enhancement of the quality of the parent-child relationship, strengthening family relationships, and thereby helping to improve the developmental outcome of the children of these incarcerated mothers and fathers.

While improving the quality of parenting for incarcerated parents may be one key point of intervention, it is worth reiterating that a number of factors beyond the direct reach of parenting and parent training programs impact children's risk of eventually becoming justice involved. As reviewed earlier, the research literature, which includes large-scale longitudinal studies such as the Dunedin Multidisciplinary Health and Development Study (e.g., Poulton et al., 2015), has identified other contributing factors that pose significant risks for later involvement with the justice system including personality characteristics, neurodevelopmental deficits, genetic risk factors, poverty, physical health, and other family stressors (e.g., Besemer et al., 2011; Caspi et al., 2002; Elkins et al., 1997; Messer et al., 2006; Poulton, Moffitt, \& Silva, 2015; Trzesniewski et al., 2006; Viding, Blair, Moffitt, \& Plomin, 2005).

It is worth noting that within this county and throughout most of California, a majority of the parenting programs are behavioral and therefore focus primarily on teaching behavioral skills. Research suggests that outcomes using behavioral training often do not sustain improvement in a way that parents can implement the learned skills, especially during times of high distress--which is when these parenting skills are most needed. That is, the literature has documented that parents without assistance in changing their attitudes toward parenting and developing greater empathy for their children have difficulty being consistent and responding in developmentally-appropriate ways, especially when the parents are emotionally distressed (e.g., Suchman et al., 2004; Suchman, Pajulo, DeCoste, \& Mayes, 2006). Behavioral parent training programs may help with the short-term management of a child's behavior, but studies suggest that they do not show improvements in the emotional quality of the parent-child relationship nor do they address the needs that underlie a child's behavior; further, they do not foster improvements in the child's psychological functioning (e.g., Moretti, Holland, Moore, \& McKay, 2004; Suchman et al., 2004, 2006). Attachment-based parent training programs may be especially useful with at-risk populations as they address parents' own emotional histories and focus on increasing parents' attunement to their child, improving the emotional quality of the parent-child relationship, and reframing parent-child conflicts-- thereby reducing child behavior problems and improving children's 
psychological functioning (e.g., Moretti et al., 2004; Suchman et al., 2004, 2006). One of the benefits of our current parenting program is that it provides empathy for the parent in terms of how they were parented or raised, which in turn helps them develop empathy for how they are currently raising their own children. In this way, parents are better able to change their attitudes (and hence behaviors) toward parenting (e.g., Sroufe et al., 2005). For example, parents in many of the groups have said, "Parenting is about the children's needs, isn't it? I never realized that before now.'

Following this change in approach and attitude, parents learn specific positive parenting skills and have a greater ability to use them, especially in times of high distress, because the program involves both attitude change and skill development. This is consistent with the views that family relationships are important and that developing family strengths and teaching guidance skills will help families involved in the criminal justice system help their children develop prosocial, thoughtful coping (Tolan \& McKay, 1996).

\section{Impact of Parenting Education on Psychological Distress}

The finding that the parenting class also resulted in decreased symptoms of psychological distress (i.e., somatization, depression, and anxiety) for the female participants is consistent with other research studies showing that parenting education can improve participants' mental health and well-being, including self-efficacy, depression, anxiety, and stress (e.g., Loper \& Tuerk, 2011). These effects are noteworthy since parental distress is associated with impaired parenting behaviors (e.g., insensitivity, intrusiveness, controllingness, and inconsistent responsiveness), putting children at high risk for developing insensitive attachments as well as internalizing and externalizing behaviors (e.g., Hughes \& Baylin, 2012). Our parenting class may have had this effect on the female participants because our clinically-trained parent educators show empathy for them and help them to better understand their own childhoods in terms of how they impact past as well as current behaviors (including partner relationships). In addition, the parent educators empower class participants with child guidance skills, child development knowledge, and assist them in understanding sources of stress and ways to cope with it.

\section{Limitations and Future Research}

The results of this study should be interpreted cautiously due to several important limitations of this study's design.

First, as mentioned earlier, the use of a pre-post design without the benefit of a matched control group limits the ability to draw definitive conclusions as to whether the intervention was responsible for the change in scores and the significance of the effect sizes. Thus, the potential impact of other possible confounding factors on the change in scores cannot be ruled out. Future studies that include a matched control group would help clarify the effectiveness of this intervention.

Second, without the inclusion of actual parent-child interactions in the study design, it is unclear whether the change in scores translates into actual changes in parent behavior towards the child. Future studies that include pre/post observational assessments of parent-child dyadic interactions (e.g., parental sensitivity, responsiveness, use of positive child guidance vs. punishment strategies, etc.) would be valuable in assessing the overall effectiveness of the current parent training program.

Third, longitudinal follow-up assessments that include observed parent-child interactions could be utilized to determine whether such attitudinal as well as behavioral changes can be sustained over time- this would also help to evaluate the long-term effectiveness of this parent training intervention. (This was not been possible in the current study because of the inability to track our incarcerated parents post-release.) Further, longitudinal studies that track the developmental outcomes of these children could also address the long-term effectiveness of this program.

Fourth, the effects of this parent training program for parents with histories of substance abuse and family violence are unclear and were not specifically assessed in the current study. Although Harm et al. (1998) found no difference between incarcerated substance abusing women vs. other women in pre/post parenting class measures of self-esteem and the AAPI (utilizing the 15-week Nurturing Parenting Program [Bavolek \& Comstock, 1985]), having been personally victimized did impact scores. The researchers concluded that substance abusing women benefited in similar ways from parenting class. Future research could address whether 
an attachment-based parent training program would be effective for incarcerated parents with substance abuse and/or domestic violence histories.

Finally, future interventions could also consider a reentry program post-release for families that can provide continuity for the family support system, parenting support, social services, screening, and counseling services. It is important that penal systems assist parents in sustaining their attachment bonds with their children and be effective parents post-release.

\section{Conclusions}

In conclusion, our curriculum, with its focus on attachment and positive child guidance utilizing a psychotherapeutic approach, may be one important component for the creation of an effective intervention for incarcerated parents and their children. As likely recipients of poor-quality parenting growing up, and being at-risk for providing poor-quality parenting to their own children, incarcerated men and women stand to benefit from parenting education that may help improve the developmental outcomes of their children and lessen the risk that they too may become justice involved.

\section{References}

Arnsbro, M. (2008). Using attachment theory with offenders. Probation Journal, 55, 231-244. doi: http:// dxdoi.org/10.1177/0264550508092812

Bailey, A. \& Hayes, J. (2006). Who's in Prison? California Counts: Public Policy Institute of California, 8, $1-28$.

Barnes, G. \& Farrell, M. (1992). Parental support and control as predictors of adolescent drinking, delinquency, and related problem behaviors. Journal of Marriage and Family, 54(4), 763-776.

Bavolek, S. \& Comstock, C. (1985). Nurturing program for parents and children. Eau Claire, WI: Family Development Resources.

Bavolek, S.J \& Keene, R.G. (2001). Adult-Adolescent Parenting Inventory AAPI-2: Administration and Development Handbook. Park City, UT: Family Development Resources, Inc.

Belsky, J., Steinberg, L., \& Draper, P. (1991). Childhood experience, interpersonal development, and reproductive strategy: An evolutionary theory of socialization. Child Development, 62, 647-670. doi: https:// doi.org/10.2307/1131166

Berlin, L. J. \& Cassidy, J. (2003). Mothers' Self-Reported Control of Their Preschool Children's Emotional Expressiveness: A Longitudinal Study of Associations with Infant-Mother Attachment and Children's Emotion Regulation. Social Development, 12(4), 477-495. doi: https://doi.org/10.1111/1467-9507.00244

Besemer, S., van der Geest, V., Murray, J., Bijleveld, C., \& Farrington, D. (2011). The relationship between parental imprisonment and offspring offending in England and the Netherlands. British Journal of Criminology, 51, 413-437. doi: https://doi.org/10.1093/bjc/azq072

Bilchik, S., Seymour, C., \& Kreisher, K. (2001). Parents in prison. Corrections Today, 63, 108-111.

Calkins, S. D. (2004). Early attachment processes and the development of emotional self-regulation. In R. F. Baumeister, K. D. Vohs, R. F. Baumeister, K. D. Vohs (Eds.), Handbook of self-regulation: Research, theory, and applications (pp. 324-339). New York, NY, US: Guilford Press.

Caspi, A., McClay, J., Moffitt, T., Mill, J., Martin, J., Craig, I., Taylor, A., \& Poulton, R. (2002). Role of genotype in the cycle of violence in maltreated children. Science, 297, 851-854. doi: https://doi.org/10.1126/ science. 1072290

Caulkins, S.D., Smith, C.L., Gill, K.L., \& Johnson, M.C. (1998). Maternal interactive style across contexts: Relations to emotional, behavioral, and physiological regulation during toddlerhood. Social Development, 7, 350-369. doi: https://doi.org/10.1111/1467-9507.00072

Campbell, S., Shaw, D.S., \& Gilliom, M. (2000). Externalizing behavior problems: Toddlers and preschoolers at risk for later maladjustment. Development and Psychopathology, 12, 467-488. doi: https://doi. 


\section{org/10.1017/S0954579400003114}

Cassidy, J. \& Shaver, P. R. (2016). Handbook of attachment: Theory, research, and clinical applications (3rd ed.). New York, NY, US: Guilford Press.

Chesney-Lind, M. (1997). The female offender: Girls, women and crime. Thousand Oaks: Sage Publications, Inc.

Codd, H. (2007). Prisoners' families and resettlement: A critical analysis. Howard Journal of Criminal Justice, 46(3), 255-263. doi: https://doi.org/10.1111/j.1468-2311.2007.00472.x

Coleman, P. K. \& Karraker, K. H. (2000). Parenting self-efficacy among mothers of school-age children: Conceptualization, measurement, and correlates. Family Relations, 49(1), 13-24. doi: https://doi.org/10.1111/ j.1741-3729.2000.00013.x

Coleman, P. K. \& Karraker, K. H. (2003). Maternal self-efficacy beliefs, competence in parenting, and toddlers' behavior and developmental status. Infant Mental Health Journal, 24(2), 126-148. doi: https://doi. org/10.1002/imhj.10048

Conners, N.A., White-Mansell, L., Deere, D., Ledet, T., \& Edwards, M.C. (2006). Measuring the potential for child maltreatment: The reliability and validity of the Adult Adolescent Parenting Inventory-2. Child Abuse and Neglect, 30, 39-53. doi: https://doi.org/10.1016/j.chiabu.2005.08.011

Conway, J. \& Jones, E. (2015). Seven out of ten? Not even close. Central Connecticut State University, Institute for Municipal and Regional Policy. Children with Incarcerated Parents Initiative. Retrieved from https://www.ccsu.edu/imrp/Publicatons/Files/CIP_Seven_Out_of_Ten_Not_Even_Close.pdf.

Cozolino, L. J. (2005). The impact of trauma on the brain. Psychotherapy in Australia, 11(3), 22.

Crittenden, P. (2008). Raising parents: Attachment, parenting, and child safety. Portland, OR: Willan Publishing.

Dallaire, D. (2007). Children with incarcerated mothers: Developmental outcomes, special challenges, and recommendations. Journal of Applied Developmental Psychology, 28, 15-24. doi: https://doi. org/10.1016/j.appdev.2006.10.003

Dallaire, D., Loper, A.B., Poehlmann, J., \& Shear, L.D. (2010). Children's contact with their incarcerated parents. American Psychologist, 65 (6), 575-598. doi: https://doi.org/10.1037/a0020279

D’Andrea, W., Ford, J., Stolbach, B., Spinazzola, J., \& van der Kolk, B. (2012). Understanding interpersonal trauma in children: Why we need a developmentally appropriate trauma diagnosis. American Journal of Orthopsychiatry, 82, 187-200. doi: https://doi.org/10.1111/j.1939-0025.2012.01154.x

Derogatis, L. R. (1994). Symptom Checklist-90-Revised: Administration, scoring, and procedures manual. Minneapolis (MN): National Computer Systems. doi: http://dxdoi.org/10.1002/9780470449216.corpsy0970

Derogatis, L. R. (2000). Brief Symptom Inventory-18. Minneapolis, MN: NCS Pearson.

Derogatis, L.R. \& Spencer, M.S. (1982). The Brief Symptom Inventory (BSI): Administration, scoring, and procedures manual. Baltimore, MD: Johns Hopkins University School of Medicine, Clinical Psychometrics Research Unit.

Dowling, S. \& Gardner, F. (2005). Parenting programmes for improving the parenting skills and outcomes for incarcerated parents and their children. The Cochrane Database of Systematic Reviews 4. doi: https://doi. org/10.1002/146551858.CD005557.pub2

Drakeford, W. (2002). The impact of an intensive program to increase the literacy skills of youth confined to juvenile corrections. Journal of Correctional Education, 139-144.

Eddy, J. M. \& Reid, J. B. (2003). The adolescent children of incarcerated parents. Prisoners once removed: The impact of incarceration and reentry on children, families, and communities, 233-258.

Elkins, I., Iacono, W., Doyle, A., \& McGue, M. (1997). Characteristics associated with the persistence of antisocial behavior: Results from recent longitudinal research. Aggression and Violent Behavior, 2(2), 
101-124. doi: https://doi.org/10.1016/S1359-1789(96)00013-4

Farrington, D. P., Jolliffe, D., Loeber, R., Stouthamer-Loeber, M., \& Kalb, L. M. (2001). The concentration of offenders in families, and family criminality in the prediction of boys' delinquency. Journal of Adolescence, 24(5), 579-596. doi: https://doi.org/10.1006/jado.2001.0424

Farrington, D. P. \& West, D. J. (1990). The Cambridge study in delinquent development: A long-term follow-up of 411 London males. In H.J. Kerner \& G. Kaiser (Eds.), Ruminalitat, Personlickkeit, Legenseschichte, und Verhalten (p. 115-138). Berlin, Germany: Springer Verlag. doi: https://doi.org/10.1007/978-3-642-75418$\underline{0.9}$

Field, T., Estroff, D. B., Yando, R., del Valle, C., Malphurs, J., \& Hart, S. (1996). Depressed mothers' perceptions of infant vulnerability are related to later development. Child Psychiatry and Human Development, 27(1), 43-53. doi: https://doi.org/10.1007/BF02353445

Fritsch, T. A. \& Burkhead, J. D. (1981). Behavioral reactions of children to parental absence due to imprisonment. Family Relations, 30, 83-88. doi: https://doi.org/10.2307/584240

Gabel, K. \& Johnston, D. (1995). Children of incarcerated parents. NY: Lexington Books.

Gerhardt, S. (2015). Why love matters. NY: Routledge.

Gilbaud-Wallston, J. \& Wanderson, L.P. (August 1978). Development and utility of the Parenting Sense of Competence Scale. Paper presented at the annual meeting of the American Psychology Association, Toronto.

Gilmore, L. \& Cuskelly, M. (2009). Factor structure of the Parenting Sense of Competence scale using a normative sample. Child: Care, Health, and Development, 35, 48-55. doi: https://doi.org/10.1111/j.13652214.2008.00867.x

Glaze, L. E. \& Maruschak, L. M. (2008). Parents in prison and their minor children. Special Report No. NCJ222984. Washington, DC: U.S. Bureau of Justice Statistics, U.S. Dept. of Justice.

Gordon, H. R. \& Weldon, B. (2003). The impact of career and technical education programs on adult offenders: Learning behind bars. Journal of Correctional Education, 54, 200-209.

Greene, S., Haney, C., \& Hurtado, A. (2000). Cycles of pain: Risk factors in the lives of incarcerated mothers and their children. The Prison Journal, 80(1), 3-23. doi: https://doi.org/10.1177/0032885500080001001

Greenfield, L. A. \& Snell, T. L. (1999). Women offenders (NCJ 175688). Washington, DC: U.S. Department of Justice.

Guttman-Steinmetz, S. \& Crowell, J. (2006). Attachment and externalizing disorders: A developmental psychopathology perspective. Journal of the American Academy for Child and Adolescent Psychiatry, 45(4), 440451. doi: https://doi.org/10.1097/01.chi.0000196422.42599.63

Harm, N.J. \& Thompson, P. J. (1997). Evaluating the effectiveness of parent education for incarcerated mothers. Journal of Offender Rehabilitation, 24(3-4), 135-152. doi: https://doi.org/10.1300/J076v24n03 08

Harm, N. J., Thompson, P. J., \& Chambers, H. (1998). The effectiveness of parent education for substance abusing women offenders. Alcoholism Treatment Quarterly, 16(3), 63-77. doi: https://doi.org/10.1300/ $\underline{\mathrm{J} 020 \mathrm{v} 16 \mathrm{n} 0306}$

Harper, C. C. \& McLanahan, S. S. (2004). Father absence and youth incarceration. Journal of Research on Adolescence, 14(3), 369-397. doi: https://doi.org/10.1111/j.1532-7795.2004.00079.x

Heckman, J. J. (2010). Building bridges between structural and program evaluation approaches to evaluating policy (No. w16110). National Bureau of Economic Research. doi: https://doi.org/10.3386/w16110

Henry, B., Caspi, A., Moffitt, T., \& Silva, P. (1996). Temperamental and familial predictors of violent and nonviolent criminal convictions: Age 3 to age 18. Developmental Psychology, 32(4), 614-623. doi: https://doi. org/10.1037/0012-1649.32.4.614

Hoeve, M., van der Put, C., \& van der Laan, P. (2012). A meta-analysis of attachment to parents and delinquency. Journal of Abnormal Psychology, 40, 771-785. doi: https://doi.org/10.1007/s10802-011-9608-1

Huebner, B. M. \& Gustafson, R. (2007). The effect of maternal incarceration on adult offspring involvement 
in the criminal justice system. Journal of Criminal Justice, 35(3), 283-296. doi: https://doi.org/10.1016/j. jcrimjus.2007.03.005

Hughes, D. A. \& Baylin, J. (2012). Brain-based parenting: The neuroscience of caregiving for healthy attachment. NY: WW Norton \& Company.

Jarvis, J., Graham, S., Hamilton, P., \& Tyler, D. (2004). The role of parenting classes for young fathers in prison: A case study. Probation Journal, 51(1), 21-33. doi: https://doi.org/10.1177/0264550504039227

Johnston, C. \& Mash, E. J. (1989). A measure of parenting satisfaction and efficacy. Journal of Clinical Child Psychology, 18(2), 167-175. doi: https://doi.org/10.1207/s15374424jccp1802_8

Johnston, D. (1991). Jailed mothers. Pasadena, CA: Pacific Oaks Center for Children of Incarcerated Parents.

Johnston, D. (1992). Children of offenders. Pasadena, CA: Pacific Oaks Center for Children of Incarcerated Parents.

Johnston, D. (1995). Effects of parental incarceration. In K. Gabel \& D. Johnston (Eds.), Children of incarcerated parents (p. 59-88). New York: Lexington Books.

Johnston, D. (2012). Services for children of incarcerated parents. Family Court Review, 50, 91-105. doi: ton, D.C.: U.S. Department of Justice. doi: http://dxdoi.org/10.1111/j.144-1617.2011.01431.x

Juang, L. \& Silbereisen, R. (1999). Supportive parenting and adolescent adjustment across time in former East and West Germany. Journal of Adolescence, 22(6), 719-736. doi: https://doi.org/10.1006/jado.1999.0267

Juffer, F., Bakermans-Kranenburg, M.J., \& vanIJzendoorn, M.H. (2008). Promoting positive parenting: An attachment-based intervention. Mahwah, N.J.: Erlbaum.

Kaminski, J. W., Valle, L. A., Filene, J. H., \& Boyle, C. L. (2008). A meta-analytic review of components associated with parent training program effectiveness. Journal of abnormal child psychology, 36(4), 567-589. doi: http://dxdoi.org/10.1007/s10802-007-9201-9

Kampfner, C. J. (1995). Post-traumatic stress reactions in children of imprisoned mothers. Children of incarcerated parents, 89-100.

Kates, E., Gerber, E.B., \& Casey, S. (2014). Prior service utilization in detained youth with mental health needs. Administration and Policy in Mental Health, 41, 86-92. doi: https://doi.org/10.1007/s10488-012-0438-4

Kemper, K. J. \& Rivara, F. P. (1993). Parents in jail. Pediatrics, 92(2), 261-264.

Kjellstrand, J.M., Cearley, J., Eddy, J.M., Foney, D., \& Martinez, C.R. (2012). Characteristics of incarcerated fathers and mothers: Implications for preventive interventions targeting children and families. Children and Youth Services Review, 34, 2409-2415. doi: https://doi.org/10.1016/j.childyouth.2012.08.008

Klein, S. R. \& Bahr, S. J. (1996). An evaluation of a family-centered cognitive skills program for prison inmates. International Journal of Offender Therapy and Comparative Criminology, 40(4), 334-346. doi: https://doi. org/10.1177/0306624X96404008

Knoche, L., Givens, J., \& Sheridan, S. (2007). Risk and protective factors for children of adolescents: Maternal depression and parental sense of competence. Journal of Child and Family Studies, 16(5), 684-695. doi: https://doi.org/10.1007/s10826-006-9116-z

Krueger, R., Schmutte, P., Caspi, A., Moffitt, T., Campbell, K., \& Silva, P. (1994). Personality traits are linked to crime among men and women: Evidence from a birth cohort. Journal of Abnormal Psychology, 103(2), 328-338. doi: https://doi.org/10.1037/0021-843X.103.2.328

Leventhal, T. \& Brooks-Gunn, J. (2000). The neighborhoods they live in: The effects of neighborhood residence on child and adolescent outcomes. Psychological Bulletin, 126(2), 309-337. doi: https://doi.org/10.1037/0033$\underline{2909.126 .2 .309}$

Lipsey, M. W. \& Derzon, J. H. (1998). Predictors of violent or serious delinquency in adolescence and early adulthood: A synthesis of longitudinal research. In D.P. Farrington \& R. Loeber (Eds.), Serious and violent juvenile offenders. (pgs. 86-105). Thousand Oaks, CA: Sage.

Loper, A.B. \& Tuerk, E.H. (2011). Improving the emotional adjustment and communication patterns of incarcer- 
ated mothers: Effectiveness of a prison parenting program. Journal of Child and Family Studies, 20, 89-101 doi: http://dxdoi.org/10.1007/s10826-010-9381-8

Mackintosh, V. H., Myers, B. J., \& Kennon, S. S. (2006). Children of incarcerated mothers and their caregivers: Factors affecting the quality of their relationship. Journal of Child and Family Studies, 15, 579-594. doi: https://doi.org/10.1007/s10826-006-9030-4

Makariev, D. W. \& Shaver, P. R. (2010). Attachment, parental incarceration and possibilities for intervention: An overview. Attachment \& Human Development, 12(4), 311-331. doi: https://doi. org/10.1080/14751790903416939

Maruschak, L. M., Glaze, L. E., \& Mumola, C. J. (2010). Incarcerated parents and their children: Findings from the Bureau of Justice Statistics. Children of incarcerated parents: A handbook for researchers and practitioners, 33-54.

Messer, J., Goodman, R., Rowe, R., Meltzer, H., \& Maughan, B. (2006). Preadolescent conduct problems in girls and boys. Journal of the American Academy of Child and Adolescent Psychiatry, 45(2), 184-191. doi: https:// doi.org/10.1097/01.chi.0000186403.13088.d8

Mikulincer, M. \& Shaver, P. Attachment bases of psychopathology. In Attachment in adulthood (pgs. 369-404). NY: Guilford.

Moffitt, T., Poulton, R., \& Caspi, A. (2013). Lifelong impact of early self-control. American Scientist, Sept./Oct., 352-359. doi: https://doi.org/10.1511/2013.104.1

Moretti, M., Holland, R., Moore, K., \& McKay, S. (2004). An attachment-based parenting program for caregivers of severely conduct-disordered adolescents: Preliminary findings. Journal of Child \& Youth Care Work, 19, 170-179.

Mumola, C.J. (2000). Incarcerated parents and their children. (Special Report No. NCJ 182335) Washington, D.C.: U.S. Department of Justice.

Mumola, C. J. \& Karberg, J. C. (2006). Drug use and dependence, state and federal prisoners, 2004 (pp. 1-12). Washington, DC: U.S. Department of Justice, Office of Justice Programs, Bureau of Justice Statistics. doi: https://doi.org/10.1037/e560272006-001

Murray, L. (1992). The impact of postnatal depression on infant development. Journal of Child Psychology and Psychiatry, 33, 543-561. doi: https://doi.org/10.1111/j.1469-7610.1992.tb00890.x

Murray, J. \& Farrington, D. P. (2005). Parental imprisonment: effects on boys' antisocial behaviour and delinquency through the life course. Journal of Child Psychology and Psychiatry, 46(12), 1269-1278. doi: https:// doi.org/10.1111/j.1469-7610.2005.01433.x

Murray, J. \& Farrington, D.P. (2008). Effects of parental imprisonment on children. In M. Tonry (Ed.), Crime and justice: A review of research, 37, 133-206. Chicago, Il: University of Chicago Press. doi: https://doi. org/10.1086/520070

Murray, J., Irving, B., Farrington, D., Colman, I., \& Bloxsom, C. (2010). Very early predictors of conduct problems and crime: Results from a national cohort study. Journal of Child Psychology and Psychiatry, 51(11), 1198-1207. doi: https://doi.org/10.1111/j.1469-7610.2010.02287.x

Myers, B. J., Smarsh, T. M., Amlund-Hagen, K., \& Kennon, S. (1999). Children of incarcerated mothers. Journal of Child and Family Studies, 8(1), 11-25. doi: https://doi.org/10.1023/A:1022990410036

Nesmith, A. \& Ruhland, E. (2008). Children of incarcerated parents: Challenges and resiliency, in their own words. Children and Youth Services Review, 30(10), 1119-1130. doi: https://doi.org/10.1016/j. childyouth.2008.02.006

Newman, C., Fowler, C., \& Cashin, A. (2011). The development of a parenting program for incarcerated mothers in Australia: A review of prison-based parenting programs. Contemporary Nurse: A Journal for the Australian Nursing Profession, 39(1), 2-11. doi: https://doi.org/10.5172/conu.2011.39.1.2

Odgers, C., Moffitt, T., Broadbent, J., Dickson, N., Hancox, R., Harrington, H., Poulton, R., Sears, M., Thomson, W., \& Caspi, A. (2008). Female and male antisocial trajectories: From childhood origins to adult outcomes. 
Development and Psychopathology, 20, 673-716. doi: https://doi.org/10.1017/S0954579408000333

Ohan, J. L., Leung, D. W., \& Johnston, C. (2000). The Parenting Sense of Competence scale: Evidence of a stable factor structure and validity. Canadian Journal of Behavioural Science, 32(4), 251. doi: https://doi. org $/ 10.1037 / \mathrm{h} 0087122$

Ou, S. R. \& Reynolds, A. J. (2010). Grade retention, postsecondary education, and public aid receipt. Educational Evaluation and Policy Analysis, 32(1), 118-139. doi: https://doi.org/10.3102/0162373709354334

Palmer, T. (1996). Programmatic and nonprogrammatic aspects of successful intervention. In A. Harland (Ed.), Choosing options that work: Defining the demand and evaluating the supply. (pp. 131-182. Thousand Oaks, CA: Sage.

Palusci, V. J., Crum, P., Bliss, R., \& Bavolek, S. J. (2008). Changes in parenting attitudes and knowledge among inmates and other at-risk populations after a family nurturing program. Children and Youth Services Review, 30(1), 79-89. doi: https://doi.org/10.1016/j.childyouth.2007.06.006

Patterson, G., Reid, J., \& Dishon, T. (1992). Antisocial boys. Eugene, OR: Castalia.

Perez, J.A. (1996). Inmate parenting contact visitation programs: Why implement them? American Jails, 5, 3136.

Perry, B. (2002). Childhood experience and the expression of genetic potential: What childhood neglect telss us about nature and nurture. Brain and Mind, 3, 79-100. doi: https://doi.org/10.1023/A:1016557824657

Perry, B. (2005). Maltreatment and the developing child: How early childhood experience shapes child and culture.The Margaret McCain Lecture Series.

Petterson, S. M. \& Albers, A. B. (2001). Effects of poverty and maternal depression on early child development. Child Development, 1794-1813. doi: https://doi.org/10.1111/1467-8624.00379

Phillips, S. \& Bloom, B. (1998). In whose best interest? The impact of changing public policy on relatives caring for children with incarcerated parents. Child Welfare, 77(5), 531.

Phillips, S. D. \& Dettlaff, A. J. (2009). More than parents in prison: The broader overlap between the criminal justice and child welfare systems. Journal of Public Child Welfare, 3(1), 3-22. doi: http://doi. org/10.1080/15548730802690718

Phillips, S.D. \& Harm, N.J. (1996). Responding to the needs of children of incarcerated mothers. Little Rock, AR: Centers for Youth and Families.

Phillips, S. D. \& Harm, N. J. (1997). Women prisoners: A contextual framework. Women \& Therapy, 20(4), 1-9. doi: https://doi.org/10.1300/J015v20n04 01

Piquero, A., Moffitt, T., \& Wright, B. (2007). Self-control and criminal career dimensions. Journal of Contemporary Criminal Justice, 23(1), 72-89. doi: https://doi.org/10.1177/1043986206298949

Poehlmann, J. (2005a). Incarcerated mothers' contact with children, perceived family relationships, and depressive symptoms. Journal of Family Psychology, 19, 350-357. doi: https://doi.org/10.1037/0893-3200.19.3.350

Poehlmann, J. (2005b). Representations of attachment relationships in children of incarcerated mothers. Child Development, 76, 679-696. doi: https://doi.org/10.1111/j.1467-8624.2005.00871.x

Poulton, R., Moffitt, T., \& Silva, P. (2015). The Dunedin Multidisciplinary Health and Development Study: Overview of the first 40 years, with an eye to the future. Social Psychiatry and Psychiatric Epidemiology, 50, 679-693. doi: https://doi.org/10.1007/s00127-015-1048-8

Raikes, H.A. \& Thompson, R.A. (2005). Links between risk and attachment security: Models of influence. Journal of Applied Developmental Psychology, 26, 440-455. doi: https://doi.org/10.1016/j.appdev.2005.04.003

Raimon, M., Lee, A. \& Gentry, P. (2009). Sometimes good intentions yield bad results: ASFA's effect on incarcerated parents. In Intentions and Results: A Look Back at the Adoptions and Safe Families Act (pgs. 121-129). Retrieved from http://www.urban.org/research/publication/intentions-and-results-look-back-adoption-andsafe-families-act.

Reid, J. B., Patterson, G. R., \& Snyder, J. E. (2002). Antisocial behavior in children and adolescents: A devel- 
opmental analysis and model for intervention. Washington, D.C.: American Psychological Association. doi: https://doi.org/10.1037/10468-000

Rispoli, K.M., McGoey, K.E., Koziol, N.A., \& Schreiber, J.B. (2013). The relation of parenting, child temperament, and attachment security in early childhood to social competence at school entry. Journal of School Psychology, 51, 643-658. doi: https://doi.org/10.1016/j.jsp.2013.05.007

Rogers-Adkinson, D., Melloy, K., Stuart, S., Fletcher, L., \& Rinaldi, C. (2008). Reading and written language competency of incarcerated youth. Reading \& Writing Quarterly, 24(2), 197-218. doi: https://doi. org/10.1080/10573560701808502

Roisman, G. I. \& Fraley, R. C. (2008). A behavior-genetic study of parenting quality, infant attachment security, and their covariation in a nationally representative sample. Developmental Psychology, 44(3), 831. doi: https://doi.org/10.1037/0012-1649.44.3.831

Roisman, G. I. \& Fraley, R. C. (2012). A behavior-genetic study of the legacy of early caregiving experiences: Academic skills, social competence, and externalizing behavior in kindergarten. Child Development, 83(2), 728-742. doi: https://doi.org/10.1111/j.1467-8624.2011.01709.x

Rudel, C. \& Hayes, M. L. (1990). Behind no bars. Children Today, 19(3), 20-23.

Rumbaut, R.G. (2005). Turning points in the transition to adulthood: Determinants of educational attainment, incarceration, and early childbearing among children of immigrants. Ethnic and Racial Studies, 28, 10411086.

Sandifer, J. (2008). Evaluating the efficacy of a parenting program for incarcerated mothers. The Prison Journal, 88, 423-445. doi: http://dxdoi.org/10.1177/0032885508322533

Satterfield, J.H., Faller, K.J., Crinella, F.M., Schell, A.m., Swanaon, J.M., \& Homer, L.D. (2007).A 30 year prospective follow-up study of hyperactive boys with conduct problems: adult criminality. Journal of the American Academy of Child \& Adolescent Psychiatry, 46 (5), 601-610. doi: https://doi.org/10.1097/ chi.0b013e318033ff59

Shaklee, H. \& Demarest, D. (2002). Survey of parenting practice. University of Idaho Extension.

Shaw, D., Gilliom, M., Ingoldsby, E.M., \& Nagin, D.S. (2003). Trajectories leading to school-age conduct problems. Developmental Psychology, 39, 189-200. doi: https://doi.org/10.1037/0012-1649.39.2.189

Siegel, D. \& Hartzell, M. (2013). Parenting from the inside out. NY: Tarcher.

Simpson, S., Yahner, J., Dugan, L. (2008). Understanding women's pathways to jail: Analyzing the lives of incarcerated women. The Australian and New Zealand Journal of Criminology, 4, 84-108. doi: https://doi. org/10.1375/acri.41.1.84

Smarsh, T.S. \& Myers, B. (April 2001). The influence of violence exposure and life stress on moral development and behavior problems in children of incarcerated mothers. Paper presented at the biennial meeting of the Society for Research in Child Development, Minneapolis, MN.

Sourander, A., Elonheimo, H., Niemela, S., Nuutila, A.M., Helenius, H. et al. (2006). Childhood predictors of male criminality: A prospective population-based follow-up study from age 8 to late adolescence. Journal of the American Academy of Child \& Adolescent Psychiatry, 45, 578-586. doi: https://doi.org/10.1097/01. $\underline{\text { chi0000205699.58626.b5 }}$

Sroufe, L.A., Duggal, S., Weinfield, N., \& Carlson, E. (2000). Relationships, development, and psychopathology. In Sameroff, A., Lewis, M., \& Miller, S. (Eds.), Handbook of psychopathology. NY: Kluwer Academic/ Plenum. doi: https://doi.org/10.1007/978-1-4615-4163-9_5

Sroufe, L. A., Egeland, B., Carlson, E.A., \& Collins, W.A. (2005). The development of the person. NY: Guilford.

Suchman, N., Mayes, L., Conti, J., Slade, A. \& Rounsaville, B. (2004). Rethinking parenting interventions for drug-dependent mothers: From behavior management to fostering emotional bonds. Journal of Substance Abuse Treatment, 27, 179-185. doi: https://doi.org/10.1016/j.jsat.2004.06.008

Suchman, N., Pajulo, M., DeCoste, C., \& Mayes, L. (2006). Parenting interventions for drug-dependent mothers and their young children: The case for an attachment-based approach. Family Relations, 55(2), 211-226. 
Thompson, P. J. \& Harm, N. J. (2000). Parenting from prison: Helping children and mothers. Issues in Comprehensive Pediatric Nursing, 23(2), 61-81. doi: https://doi.org/10.1080/01460860050121402

Tolan, P.H. \& McKay, M. (1996). Preventing serious antisocial behavior in inner-city children: An empirically-based family prevention program. Family Relations, 45, 148-155. doi: https://doi.org/10.2307/585285

Trice, A. D. \& Brewster, J. (2004). The effects of maternal incarceration on adolescent children. Journal of Police and Criminal Psychology, 19(1), 27-35. doi: https://doi.org/10.1007/BF02802572

Trzesniewski, K., Donnellan, M., Moffitt, T., Robins, R., Poulton, R., \& Caspi, A. (2006). Low self-esteem during adolescence predicts poor health, criminal behavior, and limited economic prospects during adulthood. Developmental Psychology, 42(2), 381-390. doi: https://doi.org/10.1037/0012-1649.42.2.381

Turner, R. \& Peck, J. (2002). Long-distance dads: Restoring incarcerated fathers to their children. Corrections Today, 64(2), 72-75.

Turney, K. (2014). The consequences of paternal incarceration for maternal neglect and harsh parenting. Social Forces, 92(4), 1607-1636. doi: https://doi.org/10.1093/sf/sot160

Viding, E., Blair, R., Moffitt, T., \& Plomin, R. (2005). Evidence for substantial genetic risk for psychopathy in 7-year olds. Journal of Child Psychology and Psychiatry, 46(6), 592-597. doi: https://doi.org/10.1111/ j.1469-7610.2004.00393.x

Wasserman, G. (2000). Prevention of serious and violent offending. Washington, D.C.: Juvenile U.S. Dept. of Justice.

West, J., Denton, K., \& Germano-Hausken, E. (2000). America’s kindergartners. U.S. Department of Education, Office of Educational Research and Improvement: Early Childhood Longitudinal Study NCES 2000-070.

Western, B. \& McClanahan, S. (2000). Fathers behind bars: The impact of incarceration on family formation. Contemporary Perspectives in Family Research, 2, 307-322. doi: https://doi.org/10.1016/S1530-3535(00)80017$\underline{5}$

Wilczak, G. L. \& Markstrom, C. A. (1999). The effects of parent education on parental locus of control and satisfaction of incarcerated fathers. International Journal of Offender Therapy and Comparative Criminology, 43(1), 90-102. doi: https://doi.org/10.1177/0306624X99431009

Wildeman, C. \& Western, B. (2010). Incarceration in fragile families. The future of children, 20(2), 157-177. doi: https://doi.org/10.1353/foc.2010.0006

Wilson, K., Gonzales, P., Romero, T., Henry, K., \& Cerbano, C. (2010). The effectiveness of parent education for incarcerated parents: An evaluation of parenting from prison. The Journal of Correctional Education, 61, 114-132.

Wilson, J. \& Howell, J. (1993). Comprehensive strategy for serious, violent, and chronic juvenile offenders. Washington, D.C.: U.S. Department of Justice.

Wright, B., Caspi, A., Moffitt, T., \& Silva, P. (1999). Low self-control, social bonds, and crime: Social causation, social selection, or both? Criminology, 37(3), 479-514. doi: https://doi.org/10.1111/j.1745-9125.1999. $\underline{\text { tb00494.x }}$

\section{Endnotes}

${ }^{1}$ These are many of the same factors that placed their parents in jail or prison (e.g., Farrington \& West, 1990).

${ }^{2}$ Some researchers have questioned the intergenerational transmission of incarceration (e.g., Conway \& Jones, 2015; Raimon et al., 2009), and have suggested that parental incarceration per se may not be a causal factor in children of incarcerated parents being at higher risk for becoming justice-involved themselves, but rather it is likely due to the factors mentioned above (e.g., increased risk of mental health problems, more externalizing behaviors, growing up in poor-quality neighborhoods, etc.).

${ }^{3}$ Some measures (e.g., the Brief Symptom Inventory) were introduced later in the study, resulting in unequal numbers of participants among the measures.

${ }^{4}$ The effect sizes noted here should be viewed cautiously due to the limitations of the participant-only design without a control group. 
N. Laura Kamptner is a professor of human development in the Psychology Department at California State University, San Bernardino. She teaches courses in child/human development, parenting, child guidance, and the history of childhood, and works with several community parenting education projects which includes the local jail system. Her research interests focus primarily on the impact of early parenting quality on later outcome, especially mental health.

Dr. Faith Teyber is a clinical psychologist who grew up in South Africa and was trained at UCLA. Her research interests have been in the area of resilience in high-risk families and in clinical training of graduate students. Her most recent book with Edward Teyber is "Interpersonal process in therapy: An integrative model."

Nicholas Rockwood is currently a Ph.D. student at The Ohio State University in quantitative psychology.

Dolly Drzewiecki, B.A. in Psychology, currently works in several social programs, including providing bilingual support to new and expectant parents. 